\title{
Origin-related study of genetic diversity and heteroplasmy of Mongolian sheep (Ovis aries) using mitochondrial DNA
}

\author{
Yi Seul Kim ${ }^{1,2}$, Khaliunaa Tseveen ${ }^{2}$, Badamsuren Batsukh ${ }^{3}$, Jiyeon Seong ${ }^{4}$ and Hong Sik Kong ${ }^{1,2,4, *}$ \\ ${ }^{1}$ Hankyong and Genetics, Anseong 08826, Korea \\ ${ }^{2}$ The Graduate School, Department of Animal Life and Environment Science, Hankyong National University, Anseong \\ 08826, Korea \\ ${ }^{3}$ Department of Biotechnology and Breeding, Mongolian University of Life Sciences, Ulaanbaatar 17024, Mongolia \\ ${ }^{4}$ Genomic Informatics Center, Hankyong National University, Anseong 08826, Korea
}

Received June 5, 2020

Revised June 22, 2020

Accepted June 23, 2020

*Correspondence

Hong Sik Kong

E-mail: Kebinkhs@hknu.ac.kr

ORCID

https://orcid.org/0000-0003-1144-016X

\begin{abstract}
Food and agricultural production sector, especially livestock production is vital for Mongolia's economic and social development. Domestic sheep play key roles for Mongolians, providing food (meat, milk) and raw materials (wool, sheepskin), but genetic diversity, origin of sheep populations in Mongolia have not been well studied. Studies of population genetic diversity is important research field in conservation and restoration of animal breeds and genetic resources. Therefore, this study aimed to investigate genetic characteristics and estimate origin through the analysis of mitochondrial DNA control region D-loop and Cytochrome $b$ of Mongolian indigenous sheep (Mongolian native, Orkhon and Altanbulag) and one Europe sheep (Suffolk). As a result of there were found, 220 SNPs (Single nucleotide polymorphism) in the D-loop region, 28 SNPs in the Cytochrome B region, furthermore, 77 Haplotypes. The nucleotide diversity was only found in D-loop region $(n=0.0184)$. Phylogenetic analysis showed that 3 (A, B, and C) of 5 haplogroups of sheep have been identified in our research. Haplogroup $C$ was only found in Mongolian indigenous sheep. Haplogroup $\mathrm{D}$ and $\mathrm{E}$ were not observed. As a result of haplogroups, haplogroup $\mathrm{A}$ was dominant ( $n=46$ of 94 sheeps), followed by haplogroup $B(n=36)$ and haplogroup $C(n=12)$. Sequence analysis showed that T deletion, insertion and heteroplasmy in D-loop region occurred at a high rate in Mongolian indigenous sheep population ( $T$ insertion $=47$, T deletion = 83). The heteroplasmy, which has never been found in Mongolian sheep, has been newly discovered in this study. As a result, the Mongolian sheep varieties, which mainly derived from Asia, were in hybridization with European sheep varieties.
\end{abstract}

Keywords: genetic diversity, Haplotype, heteroplasmy, mitochondrial DNA, Mongolian sheep

\section{INTRODUCTION}

Domestic sheep (Ovis aries) have played important roles in diverse human societies as a source of food, hide, and wool, and are one of the major components of agropastoral societies since the Neolithic (Chen et al., 2006). In the 21 st century, where various industries emerged and technology developed, Mongolia continues to play a 
socio-economic role in animal husbandry (Yu, 2012). In Mongolia, compared to other types of livestock, such as goats, horse, cattle, and camels, Mongolian sheep have been a dominant domestic animal since ancient times. The sheep population comprised $>60 \%$ of total domestic animals in Mongolia (Onolragchaa et al., 2019). Mongolia supported 32.2 million heads of sheep in the 2019 census, sheep account for $45.5 \%$ of all livestock, the thirteenth largest population in the world (NSO, 2019). In addition, Mongolian indigenous sheep (MIS) are well adapted to the harsh environment in diverse natural zones (i.e., mountain, steppe, and forest). Ten breeds or strains are currently recognized in Mongolia as morphologically and genetically distinct, although it remains unclear whether these represent breeds or strains (Onolragchaa et al., 2019).

The Mongolian native (MN) sheep is widely distributed throughout the country. The Orkhon sheep is the first Merino breed derived in Mongolia. This semi-fine wool sheep of the central steppe zone has been developed from the F1 progeny of Mongolian fat-tailed ewes and precocious Soviet Merino or Tsigai and Altay rams, which were used on successive generations of cross-breeds (Batsukh et al., 1991). The Altanbulag sheep was produced through improving the Mongolian native sheep by Hisar and Edelbay rams. Hybridization was conducted up to the F2 and F3 hybrid generations in local forest-steppe region. These hybrid generations were hybridized with each other to establish meat-fat tailed type breed. The Suffolk breed was imported from France to Mongolia. These high-grade sheeps will be used in Mongolian agriculture in accordance with the breeding strategy and policy.

As the importance of genetic resources of living organisms increases worldwide, countries around the world have recognized the economic value of genetic resources and signed the Convention on Biological Diversity (CBD) for biodiversity conservation and sustainable use of resources (Park, 2007; Choi, 2012). As such, the importance of animal genetic resources is emerging worldwide, and genetic studies related to it have been conducted. Therefore, efforts are needed to protect and secure genetic resources for sheep breeds that currently exist in Mongolia. No studies on the genetic relationships between these breeds/strains and native sheep. We found only two study that considered some common breeds of Mongolia (Luo et al., 2005; Onolragchaa et al., 2019). Mitochondrial DNA (mtDNA) polymorphisms have played a significant role in tracing the origin of specific breeds and the genetic diversity of domestic sheep and other livestock species due to their maternal mode of inheritance, have a high copy number and have a greater rate of substitution on average than nuclear genes, making them particularly useful for resolving intra-species branching (Moore, 1995). Studies performed on the control region (CR; also called the Displacement loop or D-loop) and Cytochrome B (CytB) are more variable than are other mtDNA regions. For this reason, the majority of phylogenetic studies have used these markers to investigate the genetic relationships among related breeds within species (Meadows et al., 2011). Dloop and $C y t B$ gene of mtDNA of modern sheep from a wide geographical range describe five different haplogroups (A, B, C, D, and E) (Wood et al.,1996; Hiendleder et al., 1998b; 2002; Pedrosa et al., 2005; Guo et al., 2005; Meadows et al., 2005; 2007). According to those initial studies, haplogroup A predominates in Asian sheep, while haplogroup B predominates in European sheep (Guo et al., 2005; Meadows et al., 2007). In addition haplogroups $\mathrm{D}$ and $\mathrm{E}$, the most recent lineages, were only found in the Caucasus and Turkey (Tapio et al., 2005; Meadows et al., 2007), whereas relatively rare haplotypes from Haplogroup $\mathrm{C}$ have a wide geographical distribution (Chen et al., 2006). A recent study on the complete mitochondrial genome of eighty eight Mongolian native sheep examined the relationship between two sheep breeds. The phylogenetic analysis confirms the division of domestic sheep in to the three (A, B, and $\mathrm{C}$ ) haplogroups, but T-insertion, deletion and heteroplasmy were not found (Onolragchaa et al., 2019). In this context, the purpose of our study was to evaluate the genetic diversity and to clarify the origin of the MIS using the analysis of the mitochondrial markers D-loop and CytB. By comparative analysis of specific mitochondrial markers and complex molecular phylogeny, this study aims to identify the clear descendants and interrelation of the MIS with Europe sheep.

\section{MATERIALS AND METHODS}

\section{Sample collection and DNA extraction}

In the present study, whole blood samples of Mongolian native ( $n=24)$, Orkhon ( $n=23)$, Altanbulag $(n=25)$ and Europe sheep (Suffolk) $(n=22)$ were collected from Darkhan province, Mongolia and stored at $-40^{\circ} \mathrm{C}$ until further using. DNA samples were extracted from the blood a us- 
ing the QuickGene DNA Whole blood Kit (KURABO, Japan) according the manufacturer's instruction methods. The extracted genomic DNA was used for experiments after measuring the concentration and purity using the ND-1000 UV-Vis spectrophotometer (NanoDrop Technologies, Wilmington, DE, USA). For genetic diversity and phylogenetic analysis, we amplified from the gene that or mtDNA (mitochrondrial DNA) CytB and D-loop (control region) area. $C y t B$ were amplified 743bp using primers F: 5'-GATCTCCCAGCTCCATCAAA -3' and R: 5' -TGAGGGGGAGTGTTAAGTGG -3'(Dudu et al., 2016), D-loop area were by amplified 1,055bp using primers: F: 5'-AACTCCCAAACATACAACACGG 3' and R: 5'-ATTTGAGTATTGAGGGCGGGAT-3'(Li et al., 2006). PCR was performed in a total reaction volume of $15 \mu \mathrm{L}$ containing 50-100 ng/uL of genomic DNA, $0.5 \mu \mathrm{L}$ of each primer, $1.5 \mu \mathrm{L}$ of 10x PCR buffer, $1.2 \mu \mathrm{L}$ of dNTPs, $0.2 \mu \mathrm{L}$ of Hot Start Taq DNA Polymerase and DW (distilled water) was used to perform PCR using the GeneAmp PCR system 9700 (Applied Biosystems, Foster City, CA, USA). The PCR amplification was conducted using following conditions: pre-denaturation at $95^{\circ} \mathrm{C}$ for 10 minutes followed by 35 cycles of $95^{\circ} \mathrm{C}$ for 45 seconds, $55^{\circ} \mathrm{C}-59^{\circ} \mathrm{C}$ for 45 seconds, and $72^{\circ} \mathrm{C}$ for 60 seconds. After 15 minutes of extension at $72^{\circ} \mathrm{C}$, the reaction was terminated at $4^{\circ} \mathrm{C}$. Before sequencing, the PCR products were purified using AccuPrep PCR/Gel DNA Purification Kit (BIONEER, Korea), amplified PCR product fragments were directly sequenced. The heteroplasmy was confirmed by $2 \%$ Agarose gel, and the nucleotide sequence was also confirmed.

\section{Data analysis}

The sequence was processed using DNA sequencing Analysis 5.1 Software (AppliedBiosystems), and sorted and edited using BioEdit software v.7.2.5 (Hall, 1999). DNA Sequence Polymorphism (DnaSP) v5.1 (Librado et al., 2009) was used to calculate the haplotype diversity and nucleotide diversity, number of haplotypes and mtDNA ( $C y t B$ and D-loop). Ten sheep mtDNA control reference sequences belonging to the five known haplogroups (Meadows et al., 2011) were also includes in the analysis, to facilitate the recognition of haplogroup statutus of each individual Haplogroup A (HM236174.1, HM236175.1), Haplogroup B (HM236176.1, HM236177.1), Haplogroup C (HM236178.1, HM236179.1), Haplogroup D (HM236180.1, HM236181.1) and Haplogroup E (HM236182.1, HM236183.1). We also used HaploView software (https://www.broadinstitute. org/haploview/downloads) to check the sequence and frequency of haplotypes. A phylogenetic tree was constructed with FigTree v1.4.3 Software (http://tree.bio. ed.ac.uk/software/figtree/). The Median joining (MJ) networks (Bandelt et al., 1999) was drawn using the program Network V.5.0.0.3 software to investigate the possible relationships among haplotypes and to determine the number of mutations between haplogroups.

\section{RESULTS}

\section{Mitochondrial $C y t B$ analysis}

To estimate the origin of the MIS the determined $C y t B$ sequences were edited and linked using Bioedit software and compared to already identified (Meadows et al., 2011) sheep mtDNA haplogroup reference sequences. Ovine $743 \mathrm{bp}$ of $C y t B$ sequences were examined in 94 sheep samples (72 MIS, 22 Europe sheeps), which are representing four population of sheeps raised in Mongolia (Fig. 1). In detection of total 17 haplotypes in $C y t B$ region of four sheep populations, 7 belong to Altanbulag sheep, 10 to MN sheep. In each population there were identified 5-10 haplotypes of $C y t B$ region. In the case of $C y t B$, there were found 28 SNPs, haplotype diversity was 0.7610 , which was relatively lower than D-loop. For accurate results, we used MJ network figuration to identify the phylogeny of haplotypes. The phylogenetic tree results were consistent. There were identified 3 haplogroups (A, B and C) in 17 types of haplotypes as in reference haplotypes. As a result, haplogroup A was dominanted ( $\mathrm{n}=46$ of 94 sheeps), followed by haplogroup B ( $=36)$ and haplogroup C ( $=$ 12) (Table 1). In addition, the haplogroup results of $C y t B$ were few haplotypes and reference haplogroups were not found (Fig. 2).

\section{Mitochondrial D-loop analysis}

In detection of total 76 haplotypes in D-loop region of four sheep populations, 24 haplotypes belong to Altanbulag sheep, 24 to MN sheep. In each population there were identified 21-24 haplotypes, 220 SNPs as known as hypervariable regions. We have identified 3 haplogroups (A, B and C) in 76 haplotypes as in reference haplotypes using MJ network figuration (Fig. 3). As a result, haplogroups of each sheep population in D-loop region were consistent with the result of $C y t B$ (Table 2). The haplotype 

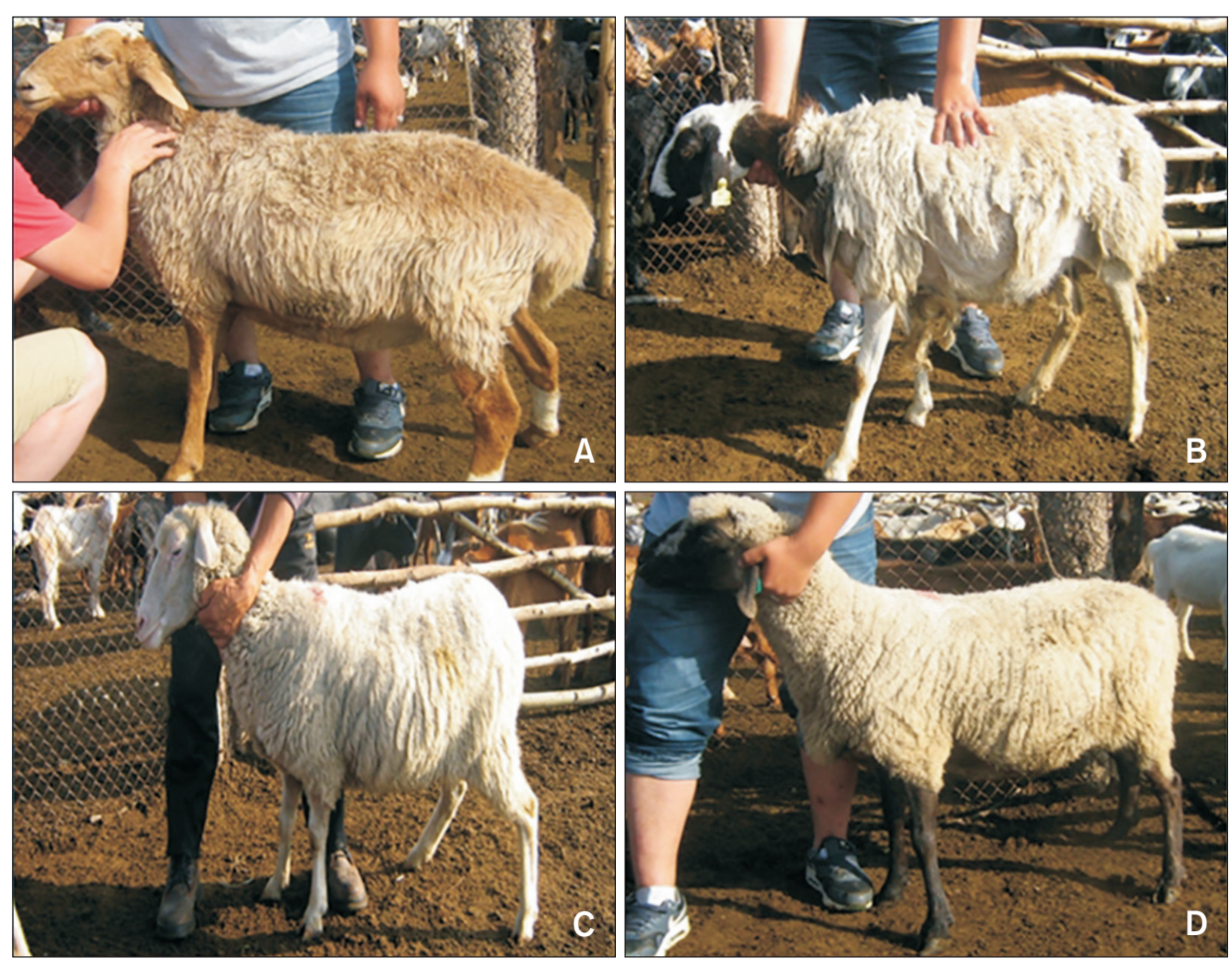

Fig. 1. Sheep examined in this study. Mongolian sheep Altanbulag sheep (A), MN sheep (B), Orkhon sheep (C), Suffolk sheep (D).

Table 1. Distribution of mtDNA CytB haplogroups of Mongolian sheep

\begin{tabular}{lccccc}
\hline \multirow{2}{*}{$\begin{array}{c}\text { Breed/ } \\
\text { population }\end{array}$} & No. of & \multirow{2}{*}{$\begin{array}{c}\text { No. of } \\
\text { hamplotype }\end{array}$} & \multicolumn{4}{c}{ Haplogroups } \\
\cline { 4 - 6 } & & sytB $)$ & A & B & C \\
\hline Altanbulag & 25 & 7 & $15(60.0 \%)$ & $6(24.0 \%)$ & $4(16.0 \%)$ \\
$\begin{array}{l}\text { Mongolian } \\
\quad \text { native }\end{array}$ & 24 & 10 & $10(41.7 \%)$ & $8(33.3 \%)$ & $6(25.0 \%)$ \\
Orkhon & 23 & 5 & $10(43.5 \%)$ & $11(47.8 \%)$ & $2(8.7 \%)$ \\
Suffolk & 22 & 7 & $11(50.0 \%)$ & $11(50.0 \%)$ & $0(0.0 \%)$ \\
Total & 94 & 29 & 46 & 36 & 12 \\
\hline
\end{tabular}

The cases with same haplotypes were from different breeds. When the haplotypes were classified by each breed, the number of haplotypes was higher.

diversity and nucleotide diversity in the mtDNA D-loop region are shown on Table 3. The haplotype diversity of Orkhon sheep (1) was relatively higher than MN sheep and Suffolk sheep (0.996). The highest nucleotide diversity was found in MN sheep (0.02105), the lowest in Suffolk sheep (0.01678). In D-loop region, SNPs were 7.8 times, haplotype was 4.5 times, and diversity was 0.2338 higher than CytB's. Furthermore, in the process of creating haplogroups using the MJ network, there were presented Heteroplasmy, $\mathrm{T}$ insertion and deletion in haplogroup $\mathrm{A}$ (Table 3). Sequence analysis showed that $\mathrm{T}$ deletion and $\mathrm{T}$

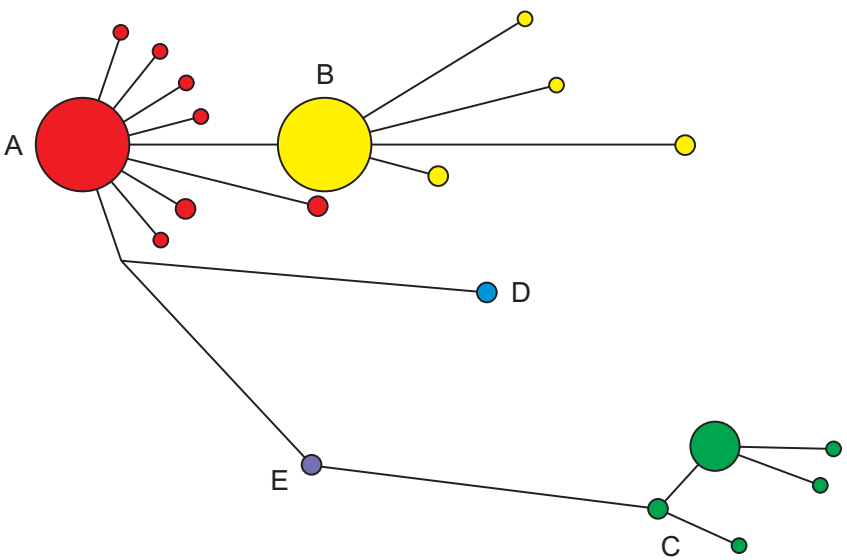

Fig. 2. Median-joining network of Mongolian sheep based on mtDNA CytB region.

insertion in D-loop occurred at a high rate in MIS population $(\mathrm{T}$ insertion $=47$, $\mathrm{T}$ deletion $=83$, Table 3$)$. $\mathrm{T}$ deletion in Suffolk sheep was 100\% (the highest), in Orkhon sheep 91.3\%, in Altanbulag sheep 88.0\%, in MN sheep $75.0 \%$ (the lowest). Among the reference haplogroups, $\mathrm{T}$ deletion was occurred only in A, B and D haplogroups. T deletions did not exist in haplogroups $\mathrm{C}$ and $\mathrm{E}$, but $\mathrm{T}$ deletions was appeared in all Suffolk sheep. It seems to be likely that it was derived from haplogroup $\mathrm{C}$ and $\mathrm{E}$.

Heteroplasmy was found in Mongolian sheep popula- 
tion, but has not been reported in previous studies. In the result of sequencing of each type, heteroplasmy was generated by deletion of 1 repeat in $75 \mathrm{nt}$ tandem repeat of diversity in the D-loop, and appeared in both of the short mutant genome and the normal genome. Heteroplasmy was discovered in 8 of 94 Mongolian sheeps (3 Altanbulag sheeps, 2 MN sheeps, 1 Orkhon sheep, 2 Suffolk sheeps;

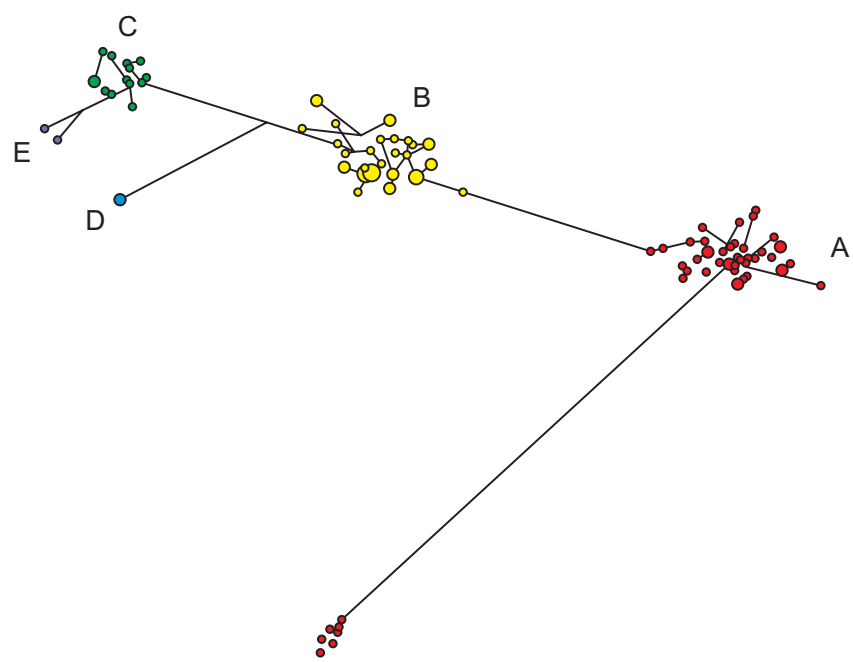

Fig. 3. Median-joining network of Mongolian sheep based on mtDNA D-loop region.

Table 2. Distribution of mtDNA D-loop haplogroups in Mongolian sheep

\begin{tabular}{|c|c|c|c|c|c|}
\hline \multirow{2}{*}{$\begin{array}{c}\text { Breed/ } \\
\text { population }\end{array}$} & \multirow{2}{*}{$\begin{array}{l}\text { No. of } \\
\text { sample }\end{array}$} & \multirow{2}{*}{$\begin{array}{c}\text { No. of } \\
\text { haplotype } \\
\text { (D-loop) }\end{array}$} & \multicolumn{3}{|c|}{ Haplogroups } \\
\hline & & & $A$ & B & $\mathrm{C}$ \\
\hline Altanbulag & 25 & 24 & $15(60.0 \%)$ & $6(24.0 \%)$ & $4(16.0 \%)$ \\
\hline Mongolian tive & 24 & 24 & $10(41.7 \%)$ & 8 (33.3\%) & $6(25.0 \%)$ \\
\hline Orkhon & 23 & 23 & $10(43.5 \%)$ & $11(47.8 \%)$ & $2(8.7 \%)$ \\
\hline Suffolk & 22 & 21 & $11(50.0 \%)$ & $11(50.0 \%)$ & $0(0.0 \%)$ \\
\hline Total & 94 & 92 & 46 & 36 & 12 \\
\hline
\end{tabular}

The cases with same haplotypes were from different breeds. When the haplotypes were classified by each breed, the number of haplotypes was higher.
Table 3). From this result, mutation has occurred in Mongolian sheep from ancient times. Therefore, in the future, more studies on Mongolian sheep breeds are needed to utilize mtDNA heteroplasmy as a breed specificity. For accurate results, to improve our understanding of the phylogenetic relationships among haplotypes with in lineages, within the sheep populations, as well as between MIS and Europe sheep, we constructed MJ network for each lineage in population with 10 references sequences retrieved from the NCBI (Genbank). When we used MJ network to combine the reference sequence's data with Mongolian sheep's data, only A, B and C haplogroups were matching. Haplogroup A was found in mainly breeds from Asia, haplogroup B observed at the highest frequency in breeds sourced from Europe (Guo et al., 2006). Haplogroup C which was first identified in Chinese sheep (Luo et al., 2005; Guo et al., 2006), occurred more often in Near East (West Asia), but were found in three population distributed in the Mongolia. D and E haplogroups did not appear in our study, which are very rare, and have

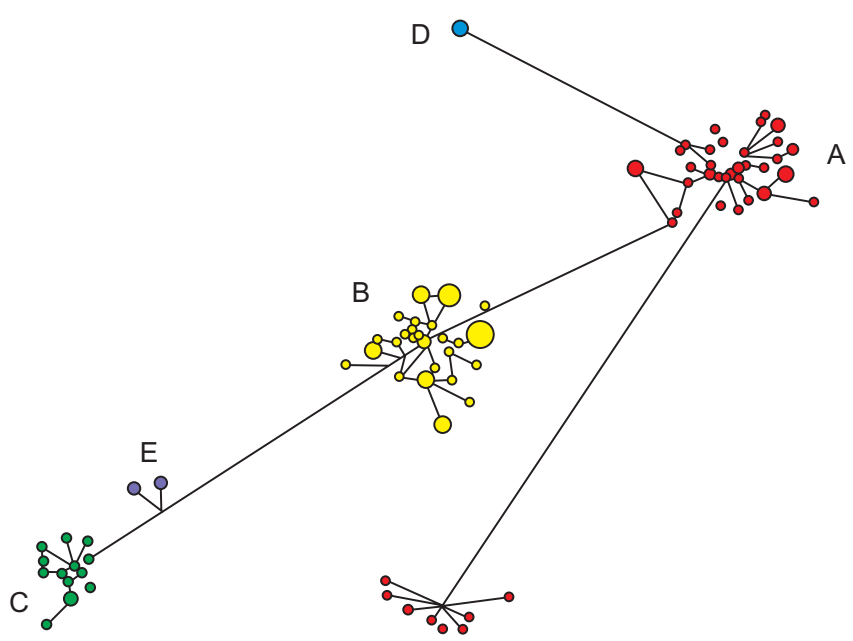

Fig. 4. Median-joining network of Mongolian sheep based on mtDNA D-loop and CytB regions.

Table 3. Distribution of mtDNA D-loop nucleotide, Haplotyde diversity, T insertion, deletion and heteroplasmy in Mongolian sheep

\begin{tabular}{lcccccc}
\hline \multirow{2}{*}{ Breed/population } & No. of sample & \multicolumn{2}{c}{ Indel } & Nucleotide & $\begin{array}{c}\text { Haplotype } \\
\text { diversity }\end{array}$ & $\begin{array}{c}\text { Heteroplasmy } \\
\text { (ratio) }\end{array}$ \\
\cline { 3 - 5 } & & Insertion & Deletion & & 0.997 & $3(12.0 \%)$ \\
Altanbulag & 25 & $15(60.0 \%)$ & $22(88.0 \%)$ & 0.01806 & 0.996 & $2(8.3 \%)$ \\
Mongolian native & 24 & $10(41.7 \%)$ & $18(75.0 \%)$ & 0.02105 & 1 & $1(4.2 \%)$ \\
Orkhon & 23 & $11(47.8 \%)$ & $21(91.3 \%)$ & 0.01771 & 0.996 & $2(9.1 \%)$ \\
Suffolk & 22 & $11(50.0 \%)$ & $22(100.0 \%)$ & 0.01678 & & $8(8.5 \%)$ \\
Total & 94 & $47(50.0 \%)$ & $83(88.3 \%)$ & & & \\
\hline
\end{tabular}




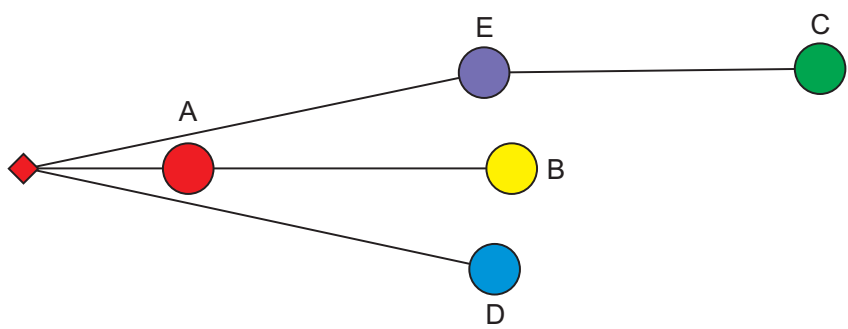

Fig. 5. Median-joining network of sheep reference haplogroup A-E based on mtDNA CytB region. Haplo Group A: HM236174.1 (Merino), HM236175.1 (Romney); Haplo Group B: HM236176.1 (Karakas), HM236177.1 (Karakas); Haplo Group C: HM236178.1 (Karakas), HM236179.1 (Morkaraman); Haplo Group D: HM236180.1 (Morkaraman) HM236181.1 (Morkaraman); Haplo Group E: HM236182.1 (Awassi), HM236183.1 (Tuj).

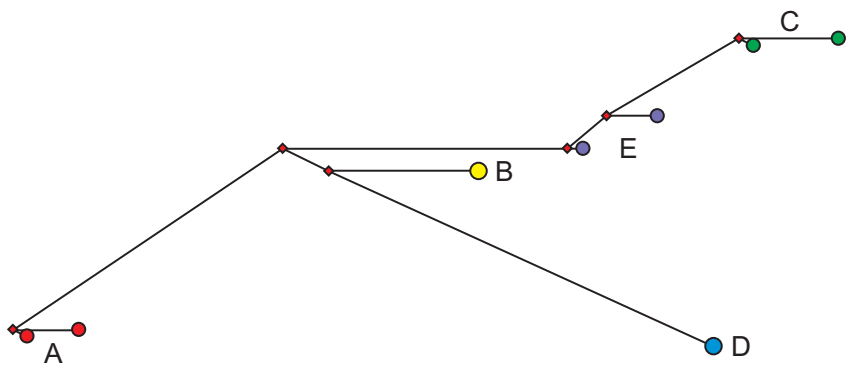

Fig. 6. Median-joining network of sheep reference haplogroup A-E based on mtDNA D-loop region. Haplo Group A: HM236174.1 (Merino), HM236175.1 (Romney); Haplo Group B: HM236176.1 (Karakas), HM236177.1 (Karakas); Haplo Group C: HM236178.1 (Karakas), HM236179.1 (Morkaraman); Haplo Group D: HM236180.1 (Morkaraman) HM236181.1 (Morkaraman); Haplo Group E: HM236182.1 (Awassi), HM236183.1 (Tuj).

been reported to occur only in Turkish sheep and Caucasus regions. Therefore, Mongolian sheep, which the rest of breeds except Suffolk sheep can be derived from Asia, Europe and Near East (West Asia). D and E haplogroups showed in Fig. 2, 3 and 4 are taken from reference data. In comparison to previously well-defined sheep mtDNA lineages A, B (Hiendleder et al., 1998b), and C (Guo et al., 2005; Pedrosa et al., 2005), all these 93 haplotypes of MIS and Europe sheep can be clearly grouped into these three lineages A, B, and C with 46, 36 and 12 haplotypes, respectively. Finally, the result of Haplogroup showed that the number of haplotypes of D-loop was greater than $C y t B$, but the result of haplogroup was consistent in Dloop and $C y t B$ (Table 2). Altanbulag sheep's haplogroupA was predominant at $60.0 \%$, haplogroupB was found at $24.0 \%$, and haplogroupC at $16.0 \%$. MN sheep's haplogroupA was also predominant at $41.7 \%$, haplogroupB at $33.3 \%$ and haplogroupC at $25.0 \%$. Unlike the two breeds,

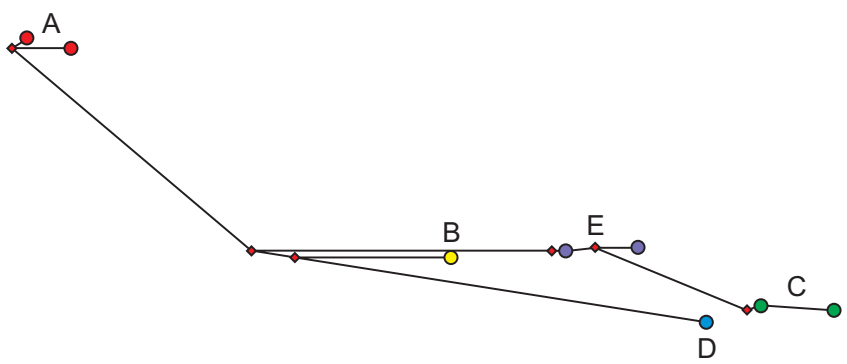

Fig. 7. Median-joining network of sheep reference haplogroup A-E based on mtDNA D-loop and CytB region. Haplo Group A: HM236174.1 (Merino), HM236175.1 (Romney); Haplo Group B: HM236176.1 (Karakas), HM236177.1 (Karakas); Haplo Group C: HM236178.1 (Karakas), HM236179.1 (Morkaraman); Haplo Group D: HM236180.1 (Morkaraman) HM236181.1 (Morkaraman); Haplo Group E: HM236182.1 (Awassi), HM236183.1 (Tuj).

Orkhon sheep's haplogroupB was predominant at $47.8 \%$, haplogroupA was found at $43 \%$, and haplogroupC at 8.7\%. Suffolk sheep's haplogroupA and haplogroupB were equal, and haplogroupC was not appeared.

\section{DISCUSSION}

As the importance of genetic resources increase around the world, it is recognized that animals' genetic resources have industrial economic value. For this reason, efforts are being made to improve genetically modified breeds with good genetic resources around the world and establish them as unique breed. In modern Mongolia, sheep are very important animal, as they still lead the industry around animal husbandry. A sheep breeds in Mongolia withstand cold and dry climate conditions and have good genetic resources. They are very important through genetic characteristics and establishment of breeds through maintaining genealogy, and efforts to secure the gene source of breeds. For this, it is essential to estimate and confirm the origin through the genetic diversity and structural studies of Mongolian sheep. This study analyzed mtDNA two regions of $C y t B$ and D-loop, which have many mtDNA mutations to estimate the origin of Mongolian sheep and to investigate the genetic diversity and structure. The data indicated an abundant genetic diversity in Mongolian sheep population. This finding is consistent with other genetic diversity studies of MIS (Luo et al., 2005; Onolragchaa et al., 2019). In this study, the haplotype diversity was higher than the results of previous studies (Chen et al., 2006; Pardeshi et al., 2007; Onolragchaa et al., 2019), whereas the nucleotide diver- 
sity was lower than the results of previous study (Chen et al., 2006). As a result of confirming MJ network and Phylogenetic tree of the Mongolian and Europe sheep, compared with ten sheep mtDNA control reference sequences belonging to the five haplogroups (Meadows et al., 2011) (Fig. 5-7). Mongolian sheep are thought to be derived from haplogroupA (Asia), B (Europe) and C (West Asia). In general, the haplogroup prevalence in present study is consistent with the previous studies on domestic sheep breeds in Asia (Luo et al., 2005; Chen et al., 2006; Pardeshi et al., 2007; Wang et al., 2007; Zhao et al., 2011; Arora et al., 2013; Singh et al., 2013).

Heteroplasmy, which caused by the diversity of 75 tandem repeat, has not been reported in previous studies of Mongolian sheep, but has been found in other animals. Studies of other mammals, such as monkey 160bp (Hayasaka et al., 1991), bat $81 \mathrm{bp}$ (Wikinson et al., 1991), rat 79bp (Stewart et al., 1994) and sturgeon 74-82bp (Ludwig et al., 2000) have confirmed that heteroplasmy occurs due to a deletion mutation of a repeating sequence in the $\mathrm{D}$ Loop region of mtDNA. Heteroplasmy is stably inherited from mother to offspring. In the case of monkeys, heteroplasmy was found in the majority of monkeys in a specific region. Based on this, heteroplasmy was maintained for several generations of the monkeys (Hayasaka et al., 1991; Wilkinson et al., 1991). Therefore, heteroplasmy is inherited, so it can be used as an indicator to identify the lineage. In the case of Mongolian sheep, there is a difference in the occurrence of heteroplasmy in each breed, but it is considered to be insignificant and difficult to be judged due to the specificity of the breed. This is not related to haplogroupC as shown in the result of $\mathrm{T}$ deletion. Different distribution patterns exist for each haplogroup (A, B, and C) of three population of Mongolian sheep breeds. Since, Mongolia is adjacent to Asian China and European Russia, MIS are crossing over two neighboring countries and considered to belong to various haplogroups. Our findings were consistent with the similar results of previous studies on domestic sheep breeds, in which haplogroup A and B were predominant in most of breeds, whereas haplogroup $\mathrm{C}$ was at low frequency in Mongolian sheep (Luo et al., 2005; Onolragchaa et al., 2019) and in other countries (Meadows et al., 2007; Singh et al., 2013; Gorkhali et al., 2015). Only in one Mongolian sheep (Altanbulag No. 44) was found haplogroup A as in reference haplogroups, while the rest were belonged to the haplogroup, but the same haplotype was not found.

\section{CONCLUSION}

In this study, we investigated the genetic diversity and origin of three MIS population and one Europe sheep population raised in Mongolia. It is vital to report that indigenous sheep populations of Mongolia retain high levels of genetic diversity based on the results from analysis of two mtDNA markers (D-loop and CytB). Phylogenetic analysis indicated that three maternal lineages (haplogroups A, B and C) were found in these breeds except Europe breed, which only had A and B haplogroups. From this result, Mongolian sheep populations were in hybridization with European sheep varieties. The heteroplasmy, which has never been found in Mongolian sheep, has been newly discovered in this study. Heritability was high, as the mutation has occurred in MIS from the ancient times. Further research will incorporate ancient sheep samples from archeological sites in Mongolia with a much large number of samples from the border area in Mongolia to contribute to a better understanding of the origin of MIS. Also additional molecular studies are required using domestic sheep from neighbor countries such as Russia and China.

\section{CONFLICTS OF INTEREST}

No potential conflict of interest relevant to this article was reported.

\section{ETHICS APPROVAL}

The study was approved by the Hankyong National University Animal Ethics Committee (No.2018-6).

\section{ACKNOWLEDGEMENTS}

The authors are grateful to Prof. Baatartsogt Oyungerel, Department of Biotechnology, Mongolian University of Life Sciences, Ulaanbaatar, Mongolia, for his helpful provide samples, comments and discussions.

\section{AUTHOR CONTRIBUTIONS}

Conceptualization: Hong Sik Kong 
Data curation: Yi Seul Kim

Formal analysis: Yi Seul Kim, Badamsuren Batsukh

Funding acquisition: Hong Sik Kong

Investigation: Yi Seul Kim, Jiyeon Seong

Methodology: Yi Seul Kim, Jiyeon Seong

Project administration: Hong Sik Kong, Jiyeon Seong

Resources: Khaliunaa Tseveen, Badamsuren Batsukh

Software: Yi Seul Kim

Supervision: Hong Sik Kong

Validation: Yi Seul Kim, Jiyeon Seong

Visualization: Yi Seul Kin, Khaliunaa Tseveen

Writing - original draft: Yi Seul Kin, Khaliunaa Tseveen

Writing - review \& editing: Khaliunaa Tseveen, Jiyeon Seong

\section{AUTHOR'S POSITION AND ORCID NO.}

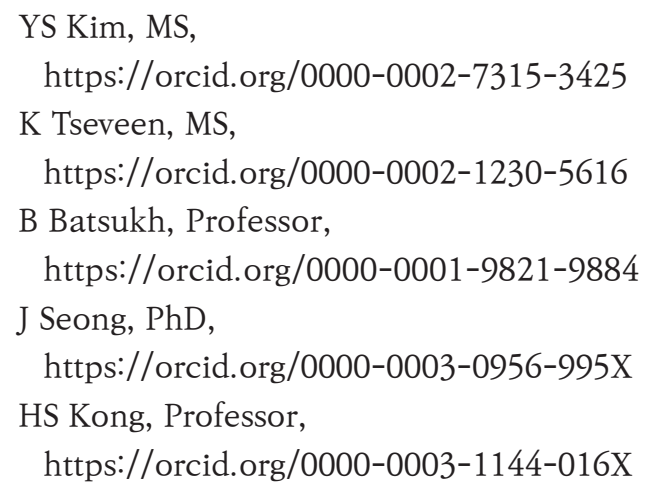

\section{REFERENCES}

Arora R, Yadav HS, Mishra BP. 2013. Mitochondrial DNA diversity in Indian sheep. Livest. Sci. 153:50-55.

Bandelt HJ, Forster P, Röhl A. 1999. Median-joining networks for inferring intraspecific phylogenies. Mol. Biol. Evol. 16:37-48.

Batsukh G and Zagdsuren E. 1991. Sheep breeds of Mongolia. World Anim. Rev. 68:11-25.

Bruford MW, Bradley DG, Luikart G. 2003. DNA markers reveal the complexity of livestock domestication. Nat. Rev. Genet. 4:900-910.

Chen SY, Duan ZY, Sha T, Xiangyu J, Wu SF, Zhang YP. 2006. Origin, genetic diversity, and population structure of Chinese domestic sheep. Gene 376:216-223.

Choi TJ, Lee SS, Yoon DH, Kang HS, Kim CD, Hwang IH, Kim CY, Jin X, Yang CG, Seo KS. 2012. Determination of genetic diversity among Korean Hanwoo cattle based on physical characteristics. Asian-Australas. J. Anim. Sci. 25:1205-1215.

Conference of the Parties to the Convention on Biological Diversity. 2010. Updating and Revision of the Strategic Plan for the Post-2010 Period, Nagoya, Japan, 18-29 October. Nagoya,
Japan: Convention on Biological Diversity.

Dudu A, Ghiţă E, Costache M, Georgescu SE. 2016. Origin and genetic diversity of Romanian Racka sheep using mitochondrial markers. Small Rumin. Res. 144:276-282.

Fumagalli L, Taberlet P, Favre L, Hausser J. 1996. Origin and evolution of homologous repeated sequences in the mitochondrial DNA control region of shrews. Mol. Biol. Evol. 13:31-46.

Gorkhali NA, Han JL, Ma YH. 2015. Mitochondrial DNA variation in indigenous sheep (Ovis aries) breeds of Nepal. Trop. Agric. Res. 26:632-641.

Guo J, Du LX, Ma YH, Guan WJ, Li HB, Zhao QJ, Li X, Rao SQ. 2005. A novel maternal lineage revealed in sheep (Ovis aries). Anim. Genet. 36:331-336.

Hayasaka K, Ishida T, Horai S. 1991. Heteroplasmy and polymorphism in the major noncoding region of mitochondrial DNA in Japanese monkeys: association with tandemly repeated sequences. Mol. Biol. Evol. 8:399-415.

Hiendleder S, Kaupe B, Wassmuth R, Janke A. 2002. Molecular analysis of wild and domestic sheep questions current nomenclature and provides evidence for domestication from two different subspecies. Proc. Biol. Sci. 269:893-904.

Hiendleder S, Lewalski H, Wassmuth R, Janke A. 1998a. The complete mitochondrial DNA sequence of the domestic sheep (Ovis aries) and comparison with the other major ovine haplotype. J. Mol. Evol. 47:441-448.

Hiendleder S, Mainz K, Plante Y, Lewalski H. 1998b. Analysis of mitochondrial DNA indicates that domestic sheep are derived from two different ancestral maternal sources: no evidence for contributions from urial and argali sheep. J. Hered. 89:113-120.

Hoelzel AR, Lopez JV, Dover GA, O’Brien SJ. 1994. Rapid evolution of a heteroplasmic repetitive sequence in the mitochondrial DNA control region of carnivores. J. Mol. Evol. 39:191-199.

Li XL, Gong YF, Liu ZZ, Zheng GR, Zhou RY, Jin XM, Li LH, Wang HL. 2006. Study on tandem repeat sequence variation in sheep mtDNA D-loop region. Yi Chuan Xue Bao 33:10871095.

Librado P and Rozas J. 2009. DnaSP v5: a software for comprehensive analysis of DNA polymorphism data. Bioinformatics 25:1451-1452.

Lopez JV, Cevario S, O’Brien SJ. 1996. Complete nucleotide sequences of the domestic cat (Felis catus) mitochondrial genome and a transposed mtDNA tandem repeat (Numt) in the nuclear genome. Genomics 33:229-246.

Ludwig A, May B, Debus L, Jenneckens I. 2000. Heteroplasmy in the mtDNA control region of sturgeon (Acipenser, Huso and Scaphirhynchus). Genetics 156:1933-1947.

Luo YZ, Cheng SR, Batsuuri L, Badamdorj D, Olivier H, Han JL. 2005. [Origin and genetic diversity of Mongolian and Chinese sheep using mitochondrial DNA D-loop sequences]. Yi Chuan Xue Bao 32:1256-1265. Chinese.

Meadows JR, Cemal I, Karaca O, Gootwine E, Kijas JW. 2007. Five ovine mitochondrial lineages identified from sheep 
breeds of the near East. Genetics 175:1371-1379.

Meadows JR, Li K, Kantanen J, Tapio M, Sipos W, Pardeshi V, Gupta V, Calvo JH, Whan V, Norris B, Kijas JW. 2005. Mitochondrial sequence reveals high levels of gene flow between breeds of domestic sheep from Asia and Europe. J. Hered. 96:494-501.

Moore WS. 1995. Inferring phylogenies from mtDNA variation: mitochondrial-gene trees versus nuclear-gene trees. Evolution 49:718-726.

NSO: National Statistics Office of Mongolia. 2017. Government III building. http://www.1212.mn/tables.aspx?TBL_ID=DT_ NSO_1001_021V1 accessed 21 April 2018 accessed 7 April, 2020

Onolragchaa G, Lee SH, Seo D, Paek WK, Manjula P, Munkhbayar M ,Lee JH. 2019. Genetic diversity and the origin of Mongolian native sheep. Livest. Sci. 220:17-25.

Pardeshi VC, Kadoo NY, Sainani MN, Meadows JR, Kijas JW, Gupta VS. 2007. Mitochondrial haplotypes reveal a strong genetic structure for three Indian sheep breeds. Anim. Genet. 38:460-466

Park YH. 2007. Analysis of a cross-cutting issue, 'Access to Genetic Resources and Benefit-sharing' of the Conference of the Parties to the Convention on Biological Diversity. J. Environ. Policy 6:41-60.

Pedrosa S, Uzun M, Arranz JJ, Gutiérrez-Gil B, San Primitivo F, Bayón Y. 2005. Evidence of three maternal lineages in Near Eastern sheep supporting multiple domestication events. Proc. Biol. Sci. 272:2211-2217.

Singh S, Kumar Jr. S, Kolte AP, Kumar S. 2013. Extensive varia- tion and sub-structuring in lineage A mtDNA in Indian sheep: genetic evidence for domestication of sheep in India. PLoS One 8:e77858.

Stewart DT and Baker AJ. 1994. Patterns of sequence variation in the mitochondrial D-loop region of shrews. Mol. Biol. Evol. 11:9-21.

Tapio M, Marzanov N, Ozerov M, Ćinkulov M, Gonzarenko G, Kiselyova T, Murawski M, Viinalass H, Kantanen J. 2006. Sheep mitochondrial DNA variation in European, Caucasian, and Central Asian areas. Mol. Biol. Evol. 23:1776-1783.

Wang X, Ma YH, Chen H, Guan WJ. 2007. Genetic and phylogenetic studies of Chinese native sheep breeds (Ovis aries) based on mtDNA D-loop sequences. Small Rumin. Res. 72:232-236.

Wilkinson GS and Chapman AM. 1991. Length and sequence variation in evening bat D-loop mtDNA. Genetics 128:607617.

Wood NJ and Phua SH. 1996. Variation in the control region sequence of the sheep mitochondrial genome. Anim. Genet. 27:25-33.

Yu WS. 2012. The tradition and present situation of pastoral nomadism in the Mongolian plateau - with special reference to nomads, their livestock, and pasture land -. Journal of Humanities, Seoul National University 67:349-380.

Zhao Y, Zhao E, Zhang N, Duan C. 2011. Mitochondrial DNA diversity, origin, and phylogenic relationships of three Chinese large-fat-tailed sheep breeds. Trop. Anim. Health. Prod. 43:1405-1410. 